\title{
O PROBLEMA DA PAZ E O SUBDESENVOLVIMENTO ECONÔMICO
}

\author{
Ernani Guarita Cartaxo \\ Professor Catedrático da Faculdade de \\ Direito da Universidade do Paraná
}

Pode-se dizer que êste século abriu para a humanidade, com a primeira Grande Guerra, o ciclo tumultuário das largas transformações políticas e sociais, que ainda vão a meio, mas já afirmaram a predominância irreversível do sentido mundial das soluções de todos os problemas nacionais. Nunca o homem sentiu tão ìntimamente a fragilidade das grandes construções, com que o gênio nacional tem afirmado, neste ou naquele hemisfério, nos novos ou nos velhos países, o valor, o poder e a grandeza de cada povo, nos aspectos morais e materiais de sua civilização, desde que compreendeu que a predominância dos fatores externos, encadeados pelo determinismo de causas próximas ou remotas, mas sempre vigorosamente atuantes, comprometia, pela iminência dos seus efeitos, a segurança simbólica das fronteiras nacionais, empobrecidas de sentido e de realidade.

Porque a convivência das nações está exigindo novas fórmulas de entendimento, oriundas de um novo conceito de coexistência internacional, fundado, não no velho princípio da independência ou da soberania das nações, mas exatamente da interdependência dos povos, a palavra dos internacionalistas é solicitada por quantos sentem a gravidade do momento e sabem que só a inteligência e a sabedoria dos homens afeitos aos problemas das relações extra-nacionais podem ditar, nas lições das Universidades, nos debates parlamentares, nas tribunas populares, na doutrina dos livros ou nos artigos 
da imprensa, nas convenções diplomáticas e nos congressos internacionais, a mensagem tranquilizadora, que há de semear no espírito dos homens a certeza de um necessário entendimento entre os povos, amadurecido ao calor da sua própria e progressiva espiritualidade, tanto mais fácil de afirmarse quanto menores forem as desigualdades que distinguem os grupos nacionais, no plano da civilização e da cultura, e isso pelo aprimoramento paritário das condições de existência de tôda a humanidade, decorrente da supressão gradativa das zonas humanas marcadas pelo atraso, pela miséria, pela ignorância, pelo servilismo econômico, pelo primarismo social, pelo colonialismo moral e material.

Mas, sem dúvida, o problema, em que extremam tôdas as contingências resultantes do regime de insegurança, em que se debate o mundo, não é outro senão o problema da paz, na polifórmica expressão dos seus aspectos, tão instáveis como a fisionomia mutável das ameaças, que a comprometem, e das quais é a "guerra fria" a mais típica, porque mais acorde com a irresistibilidade dos engenhos da moderna técnica de destruição, acionados que podem ser na vertigem de um segundo para desfêcho de uma luta sem início.

Se em resguardo da paz a velha e nobre ONU corporifica o melhor e mais ostensivo instrumento de contenção das ameaças de guerra, não lhe faltam censuras à fragilidade de sua atuação repressiva, que se decorre, é verdade, de vícios da sua sistemática orgânica, tem a agravá-la a coincidência de figurarem entre as cinco potências constitutivas do seu Conselho de Segurança, como membros permanentes, exatamente aquelas duas, que polarizam os dois mundos em conflito aberto, o do Ocidente, liberal - democrático, e o do Oriente, totalitário - comunista.

Ademais disso, entre aquêles vícios institucionais, está o de que o quorum, exigido para a aprovação das suas deliberações, impõe a concordância dos votos dos cinco membros permanentes do Conselho, o que quer dizer que, nas questões de fundo, que concernem diretamente à defesa da paz, cada uma das grandes potências dispõe da faculdade de vetar sumàriamente qualquer deliberação, ainda que aprovada pelos demais membros, e dessa forma o direito de veto emperra o funcionamento da ONU e lhe tolhe não só a aplicação dos 
meios conciliatórios, mas principalmente as faculdades coercitivas ou o regime das sanções, sejam diplomáticas ou econômicas, sejam militares, que a Carta lhe confere.

Dessa forma, várias causas respondem pela debilidade das intervenções do Conselho de Segurança em favor da manutenção da paz, e entre estas está o uso constante e sistemático do direito de veto por parte de um dos seus membros permanentes; estão as divergências inconciliáveis dos cinco grandes acêrca dos problemas fundamentais da segurança coletiva; está a falta de acôrdos preliminares para a organização de uma fôrça armada internacional de mobilização imediata em caso de ameaça ou agressão efetiva contra a paz.

Se não se negam aplausos à larga e luminosa folha de serviços que a Organização das Nações Unidas tem prestado à humanidade, na defesa da paz, pela sua denodada contribuição para diminuir as tensões internacionais, que cada dia se agravam, "tensão entre os Estados democráticos e os Estados comunistas, tensão entre os Estados colonizadores e os Estados anti-colonialistas, tensão entre o mundo árabe e o mundo cristão, tensão entre os povos de raça branca e os povos de côr", não têm faltado sugestões para a correção dos defeitos do sistema da ONU, ou pela direta reforma de sua Carta ou pela prática de providências paralelas, que agrupem ou solidarizem os Estados interessados em organizações de âmbito regional, como preconiza o Prof. Joaquim da Silva Cunha, da Faculdade de Direito de Lisboa, de forma que às organizações regionais venha a caber a função de regular a vida dos Estados membros, aproveitada a solidariedade resultante das condições de vizinhança geográfica ou de afinidade cultural ou ideológica, enquanto à organização universal caberá regular a convivência da sociedade internacional, em função dos seus grandes interêsses. A descentralização dos problemas e o seu tratamento em instâncias distintas seria a terapêutica adequada para garantir a segurança de que necessitam os Estados, na lição do mestre lusitano.

Certo, no que interessa a nós outros, a preocupação da paz e da segurança continental foi sempre uma constante na evolução do pensamento político dos estadistas americanos, ainda que paradoxalmente a idéia de paz não coincidisse com o tumulto armado em que amiúde se conflitam intra moenia 
as facções crônicamente mobilizadas pelos "pronunciamentos" ou as "quarteladas", como expressão peculiar do processo político, que soem adotar as nações do continente, na sua generalidade.

A Organização dos Estados Americanos, se não é a réplica exata do modêlo de organização regional preconizado pelo professor lisboeta, vale como o mais vigoroso instrumento de preservação da paz modelado no âmbito continental, e para consecução dêsse propósito a Carta de Bogotá estabelece, entre outros, o princípio de que a agressão a um Estado americano constitui uma agressão a todos os demais Estados americanos e, por igual, o de que as controvérsias que surgirem entre dois ou mais Estados americanos deverão ser resolvidas por meio de processos pacíficos. De sua vez, o Ato de Chapultepec considera que a paz e a segurança do continente estarão em perigo, quer no caso de agressão extra-continental, quer no de agressão de um Estado americano contra outro. E em uma ou em outra dessas eventualidades põe em movimento o mecanismo de assistência mútua, por meio de sanções progressivas, proporcionais à gravidade da agressão, que vão desde a retirada dos Chefes de Missão, a ruptura das relações diplomáticas, a ruptura das relações consulares, a ruptura das relações postais, telegráficas, telefônicas e radiofônicas, a interrupção das relações econômicas, comerciais e financeiras, até o emprêgo de fôrças militares para evitar ou repelir a agressão. À semelhança da ONU, a OEA inclui, por outro lado, na programação de suas atividades, um generoso plano de assistência aos povos continentais, no propósito de promover o seu bem-estar, já lhe favorecendo a solução dos problemas de ordem política, jurídica e cultural, já lhe emprestando decisiva colaboração em favor do progresso econômico e social dos seus povos.

De há muito, a organização continental se fizera sensível à precariedade das condições econômicas das Repúblicas latino-americanas. Como assinala William Sanders, duvidava-se sôbre se a OEA havia sido, no passado, utilizada devidamente neste campo, mas o assunto ganhou nova importância com a crescente inquietação que o sub-desenvolvimento econômico e seus problemas sociais afins entraram a despertar na América Latina. No fenômeno do subdesenvolvimento, 
não é bastante ressaltar a pobreza e o baixo nível de vida popular, que sempre existiram, em certos casos em condições muito piores que as atuais, mas não despertavam reações suficientes para modificar tal estado de coisas, como as que se fazem sentir hoje com tanta violência. A diferença, no conceito do secretário geral da OEA, assenta em que atualmente não se aceitam essas condições como inevitáveis. Há hoje a firme determinação de melhorar as condições econômicas e sociais dessas regiões. Indo mais longe, já não se entende suficiente propugnar-se pelo seu progresso: é franco objetivo dessas reivindicações a obtenção de certo grau de paridade com os países altamente industrializados, no jôgo dos interêsses econômicos.

Se os problemas do subdesenvolvimento vêm sendo responsabilizados pela visível inquietação dos povos americanos, justo é que desencadeassem a série de providências que, no âmbito da política continental, os estadistas e publicistas estão preconizando, com crescente insistência, à guiza de soluções capazes de conjurar os males de uma situação suscetível de comprometer a segurança do continente, soluções que repousam em última análise na inauguração de uma política de ajuda compulsória por parte dos países mais prósperos e adiantados.

Coube exatamente ao Brasil uma das mais oportunas iniciativas dêsse teor, quando, em meados de 1958, o Presidente Kubitschek propôs aos países continentais o plano da "Operação Pan-Americana", inaugurado pelo apêlo que dirigiu ao Presidente Eisenhower, e no qual adianta haver soado a hora "de revermos fundamentalmente a política de entendimento dêste hemisfério e procedermos a um exame do que se está fazendo em favor dos ideais pan-americanos em tôdas as suas implicações". E continua: "Estaremos todos nós - é a hora de perguntar - agindo no sentido de se estabelecer a ligação indestrutível de sentimentos e interêsses, que a conjuntura grave aconselha e recomenda?". Afirmando que ninguém mais autorizado que o presidente americano para "apreciar a gravidade da pergunta", acrescenta o presidente brasileiro: "É aconselhável corrigirmos a falsa impressão de que não estamos vivendo fraternalmente nas Américas; mas além dessa operação corretiva e, para que ela seja duradoura e perfei- 
ta, devemos proceder a um verdadeiro exame de consciência, em face do pan-americanismo, e saber se estamos no bom caminho". Aderindo a essa sugestão, o Presidente dos Estados Unidos encareceu a necessidade "da adoção imediata de medidas que determinem, através de todo o continente, uma reafirmação de devotamento ao pan-americanismo e um melhor planejamento na promoção dos interêsises comuns e do bem-estar de nossos diferentes países".

À reunião preliminar de Ministros das Relações Exteriores, que se celebrou em Washington, em setembro de 1959, seguiu-se a formalização do acôrdo, em resolução aprovada pelo Conselho da OEA, e a creação do Conselho da OPA, integrada por vinte e um representantes especiais dos países americanos. Todos os problemas relacionados com o subdesenvolvimento foram levados em conta, e em especial assentaram-se recomendações sôbre o financiamento do desenvolvimento econômico e a creação de um Banco Interamericano de Desenvolvimento, com um capital previsto de mil milhões de dólares, para o qual subscreverão os países latino-americanos $55 \%$, ao lado de outras providências concernentes a novos aspectos da cooperação continental no combate ao subdesenvolvimento, firmada a opinião de que as inversões financeiras, embora essenciais, não constituem a solução do problema, desde que êste resulta preferìvelmente da falta de capacidade administrativa, técnica e diretiva dos países subdesenvolvidos, assim como da falta de facilidades educacionais para desenvolver aquela capacidade, conforme registra Sanders.

Por certo, estava o Presidente brasileiro convencido de que os males do subdesenvolvimento não podem ser erradicados sem a ajuda exterior. $O$ atraso econômico testemunha, de si, a existência de condições internas irremovíveis ao esfôrço exclusivo do meio local, ou pelo comprometimento da própria organização estatal na geração e manutenção dos fatores políticos e sociais determinantes do pauperismo, de que é vítima, ou pela fragilidade dos esforços do homem na luta contra a adversidade dos elementos naturais, a que está submetido, por influência de condições geográficas, climáticas e outras, ou pela coexistência simultânea de ambas as razões, o que é mais comum. 
De qualquer forma, desde que o subdesenvolvimento econômico assumiu, no panorama da segurança internacional, uma posição de indisfarçável importância, como elemento de inquietação continental, a solução do problema não pode ser deixada aos azares de um processo de recuperação indefinida, a cargo das possibilidades eventuais do próprio meio social atingido. Deve, sim, tal solução ser favorecida pelas organizações de caráter internacional, como as que se apontam, pois só sob o influxo do espírito de cooperação super-nacional, através dos planos de ajuda mútua, se poderá executar a contento e a prazo certo a tarefa de eliminar os fatores do subdesenvolvimento econômico, que, subalternizando os povos, comprometem a paz universal.

Segundo Lebret, no seu livro "Suicide au Survie de l'Occident", entre os obstáculos de ordem interna, que impedem o desenvolvimento harmônico e integral dos povos subdesenvolvidos, os mais importantes são talvez os de natureza psicológica, a que aludem as observações inscritas no quadro de "mesures a prendre pour le developpement economique des pays insuffisemnent developpés", organizado pela ONU, em 1951, e no qual assinalam os seus técnicos:

"Um progresso econômico rápido é impossível sem uma penosa readaptação. É preciso abandonar crenças antigas, destruir velhas instituições sociais, romper laços de casta, de raça, de religião e privar da vida confortável um grande número de pessoas,' que não se adaptam ao progresso. Muito raras são as sociedades, que aceitam tôdas as conseqüências de um progresso econômico rápido". $\mathrm{E}$ acrescentam:

“O progresso econômico rápido não é possível senão quando todos os escalões dirigentes do país o desejam firmemente e estão prontos a aceitar as suas conseqüências, isto é, a criação de uma sociedade de que sejam eliminados os privilégios políticos e sociais. Não é demais insistir sôbre o fato de que o povo se regula pelas classes dirigentes. Se os dirigentes são reacionários, egoístas e corrompidos, o povo se desencoraja e parece falho de iniciativa. Mas se os dirigentes ganham a confiança da 
nação e mostram que podem abater vigorosamente os privilégios e as desigualdades chocantes, passam a inspirar ao povo um entusiasmo pelo progresso, a que nada resistirá".

A propósito dessas observações, anota melancòlicamente Lebret ser fácil de imaginar-se quantas dificuldades a prática de um tal programa terá de vencer na maior parte dos países subdesenvolvidos, onde, de comum, os homens elevados ao poder não têm outra superioridade real afora a sua vontade de dominação. Se, ao contrário, são honestos e bem intencionados, dificuldades de outra natureza lhes vão entibiar a atividade renovadora: ou se apoiam nas Assembléias representativas, e estas paralisam a sua ação; ou impõem enèrgicamente os seus pontos de vista, e resvalam para a ditadura.

No seu apaixonado estudo sôbre a revolução cubana, Paul Sartre salienta as lamentáveis condições da administração política de Baptista, e vê nessa causa a razão decisiva da vitória de Fidel Castro, a que se juntam os elementos subsidiários das injustiças sociais, do pauperismo e da ignorância populares, do colonialismo econômico e mais reflexos obrigatórios do subdesenvolvimento.

Este, de qualquer modo, sabemos nós, é sempre uma realidade condicionada à ineficiência dos governos, quando não à influência dos seus vícios políticos e administrativos, patentes no mau uso ou no uso criminoso dos dinheiros públicos, no veso dos déficits orçamentários, na ilimitação dos empregos públicos, no favoritismo oligárquico, doméstico ou político-partidário, na supressão das franquias constitucionais, no personalismo dos agentes dos poderes do Estado, no desamor ao povo ou no desprêzo às suas necessidades mais rudimentares de segurança, de nutrição, de saúde, de instrução e de justiça.

Nem mesmo ao espírito essencialmente positivo do grande economista Arthur Lewis, o aplaudido autor da "Teoria do Desenvolvimento Econômico", em que lançou os fundamentos da moderna doutrina da produção; nem mesmo a Lewis passou desapercebida a contribuição que cabe aos governos na responsabilidade da creação ou manutenção dos estágios de subdesenvolvimento econômico dos povos. 
No conceito do Professor da Universidade de Manchester, o país será subdesenvolvido no sentido de que a sua tecnologia é atrasada em comparação com a de outro, ou no sentido de que as suas instituições são relativamente desfavoráveis ao investimento, ou no sentido de que os seus recursos de capital por habitante são baixos, quando confrontados com os de outros países, ou no sentido de que possui baixa renda per capi$t a$, ou de que é dotado de recursos naturais valiosos, minerais e outros, que ainda não foram utilizados.

À indeterminação dêsse panorama econômico agrega o economista inglês a variabilidade dos obstáculos, que impedem o desenvolvimento, na imprecisão da sua maior ou menor influência, em certo tempo e em certo lugar, seja no propósito de salientar que a deficiência é maior neste ou naquele ponto, seja no sentido de que é mais fácil de começar por aquêle do que por qualquer outro.

$\mathrm{Na}$ sua enumeração, figura em primeira linha o exemplo dos países em que o principal entrave ao desenvolvimento econômico são as instituições, ou seja, os maus governos ou as más leis. Nesses países, a salvo que as instituições se transformem, não se modificará, na sua opinião, o panorama econômico.

No conceito do mestre de Manchester, cuja obra inclui o Brasil no elenco dos países subdesenvolvidos e subpopulosos, a influência do govêrno se manifesta ainda sob outro aspecto, e isso quando êle entende favorecer, nos países menos desenvolvidos, o processo de sua industrialização. Trata-se, aí, da função pioneira dos governos, como a chama o escritor, função de inegável relevância econômica, que se destina a obviar os inconvenientes dos elevados custos iniciais das novas indústrias, intoleráveis de comum para as iniciativas pioneiras estritamente particulares.

Falando de economia, não há como não se aludir ao problema da desnutrição e da fome, que assume, no panorama do subdesenvolvimento econômico, o aspecto mais dramático das realidades humanas do mundo atual, e isso com tanto mais oportunidade quanto não se ignora que a América constitui, surpreendentemente, uma das áreas mundiais de subalimentação, incapaz de produzir os recursos necessários ao 
abastecimento de suas populações, apesar da notável extensão das suas terras férteis e do baixo índice de densidade demográfica.

Nos seus livros "Geografia da Fome" e "Geopolítica da Fome”, que figuram hoje nas estantes internacionais dos pesquisadores mais eminentes, o escritor patrício Josué de Castro situa a gravidade do problema nos seus têrmos exatos, ao relacionar a contradição existente entre as ótimas condições naturais do habitat americano e o flagelo da subnutrição, que aniquila e envilece as suas populações.

Numa das mais afortunadas regiões do mundo - $16 \%$ das terras habitáveis do planeta, contendo apenas $6 \%$ da população mundial - a condição econômica dos povos, que a habitam, é das mais lamentáveis, marcada, que se apresenta, pela fome crônica, decorrente de regimes alimentares insuficientes qualitativa e quantitativamente, e a que estão submetidos cêrca de 90 milhões de indivíduos, ou seja, dois têrços das populações, que habitam a América Latina.

Na América do Sul, particularmente, nenhum dos seus grupos humanos se mostra imune das conseqüências da fome. Apenas a fome se apresenta mais intensa em certas áreas e mais discreta em outras. Naquelas, a alimentação é extremamente defeituosa, e nela se associa a fome quantitativa com as insuficiências qualitativas específicas; nestas, as condições alimentares são menos graves, sendo quantitativamente suficiente o regime alimentar, enquanto existem fomes específicas em certos princípios nutritivos.

O primeiro setor é o mais amplo, e abrange três quartas partes da superfície territorial do continente, incluindo a metade - norte do território brasileiro. O segundo é mais reduzido: estende-se pela parte leste do continente, compreendendo as terras do centro-oeste e do sul do Brasil, parte do território paraguaio, todo o Uruguai e a região nordeste da Argentina.

Carências generalizadas de calorias, de proteínas e de certos princípios minerais caracterizam a manutenção de um regime subalimentar endêmico, que se reflete no fácies físico, moral e social do homem e constitui "um dos fatores de inferiorização das populações, que habitam nossos continentes". 
Daí os altos índices de mortalidade geral, de mortalidade infantil e de mortalidade por certas doenças infectuosas, "como manifestações indiretas dêsse estado de subnutrição crônica".

Certo, algumas causas naturais contribuem para tais resultados, como o baixo rendimento agrícola dos solos tropicais, o excesso de águas pluviais e fluviais da região amazônica, as sêcas do nordeste brasileiro, a condição das terras costeiras do Pacífico, as zonas tìpicamente desérticas do continente, mas sem dúvida, como observa o escritor brasileiro, "são mais fatores de ordem social do que fatores de ordem natural, os que determinam a precariedade e a escassez alimentares neste Continente".

Por certo, não apenas o problema da fome, mas em geral os problemas do subdesenvolvimento estão na ordem do dia, desafiando a atenção dos governos, dos políticos, dos sociólogos, dos economistas, dos internacionalistas, todos preocupados em lhes dar solução compatível com a extensão dos seus males.

Êstes, não só infelicitam o homem ou comprometem a ordem social, mas ameaçam a paz do mundo, pela pressão dos conflitos, que a desigualdade do poderio econômico dos grupos nacionais provoca, pondo em risco a segurança da civilização e os destinos da própria humanidade. 